described the same discovery. In the same year, Braconnot extended his experiments to linen rags and found that these too gave glucose under similar treatment.

The fate of glucose commercially was not one of great showing until well within modern times. Already in $\mathrm{I} 8 \mathrm{I} 4$, Napoleon was compelled to do away with the continental blockade which, though it hurt England much, hurt Europe very much more, and which, moreover, could not be enforced against the gigantic system of smuggling which it had developed. Thus let loose, the flood of colonial products, pent up for years, took its course towards the continent and simply swamped the market. The price of sugar dropped to unprecedented low levels, the more so as the competition of the beet sugar already began to be felt. Starch sugar, the manufacture of which still offered considerable difficulties, could not under the conditions maintain its existence and one factory after another was compelled to close its doors. It is doubtful whether in 1820 there existed a single establishment anywhere preparing sugar from starch for the market. Only after the sugar had created for itself its own sphere of consumption in the fermentative industries (beer, wine, etc.), which came about only very gradually and largely through the instrumentality of Lampadius in Germany, and Dubrunfaut and Payen in France, was the manufacture of glucose on a commercial scale taken up anew. Its development to the gigantic proportions of modern times is recent history.

Even in a scientific way starch sugar seemed to have lost most of its interest, judging from the scarcity of papers published on the subject in the years following its discovery. Only since the entry of Dubrunfaut into the chemical arena, who in I82I published his first paper on sugars and kept at it for the whole of his busy life, did this interest gradually revive, assuming ever larger proportions, which of course was not without influence on the industrial exploitation of this commodity.

One more point must be gone into here for the sake of completeness, although strictly speaking it goes beyond the period intended to be covered. It relates to the term "glucose" which has been used throughout this sketch synonymously with starch sugar. As a matter of fact, the name glucose was not introduced into the chemical nomenclature before I $83^{8^{I}}$ having been proposed by Dumas to designate sweet substances generally, which cannot be obtained in readily crystallizable form in contradistinction to cane or beet sugar. Into the German and apparently also the English literature the designation crept only some years afterwards. That the term has within recent years been restricted to the commercial product exclusively must be assumed as generally known, and is the natural result of the better knowledge which the chemistry of carbohydrates has given us of this substance.

Not much space will be required to trace the development of starch chemistry in directions other

1 C. R., 7 (1838). than those of hydrolysis. Particular mention deserves here the method devised by Kirchhof for the purification of starch, for which purpose he advised the use of dilute caustic potash to eliminate the glutinous matter, followed by washing. This is the only other paper the discoverer of glucose published on the subject of starch and starch sugar (the one giving the formation of sugar by germinted barley having already been mentioned above).

Of far greater importance was the observation of the beautiful blue color starch assumes when in contact with iodine, thus giving to the chemist the most sensitive indicator known for either of these two substances. The discovery of iodine in the ashes of seaweed by Courtois took place in I 8 I2, and gave rise to numerous investigations. Incidental to these, Colin and Gaultier de Claubry, of France, ${ }^{2}$ as well as Stromeyer, 3 of Hungary, observed the reaction, if such it may be called, between starch and iodine, a discovery the nature of which in later years up to the present days has formed a subject of much investigation and controversy, without having been so far satisfactorily solved. The few other papers published dealt more with details and while furnishing material for later investigations were not of sufficient importance to be dwelt on in this place.

Washington, D. C.

\section{THE DETERMINATION OF ARSENIC IN INSECTICIDES.}

By E. B. Holland. 4

Received Jan. 20, 1911.

During the past three years the writer has given considerable time to the study of arsenical insecticides, with special reference to their manufacture, composition and use, the main object of which was to provide the entomological department of this station with chemicals of known composition, suitable for an extended investigation to determine their effect in practical application under varying climatic and atmospheric conditions.

For more than a decade, the analysis of arsenicals has received marked attention because of the high value of a number of these salts as insecticides. The sale of inferior, adulterated or imitation products lacking in efficiency or causing severe injury to foliage has rendered necessary a certain amount of supervision by the agricultural experiment stations of the country. In several states special laws have been enacted to regulate the sale and to provide for an inspection of such materials. Arsenic as trioxide or pentoxide is the active constituent of these compounds, and various methods of several distinct types and numerous modifications have been proposed for its determination. Some of the methods are applicable to arsenous acid and others to arsenic acid. METHODS.

As the work planned by the entomological de-

${ }^{1}$ Schweigger's Journal. 14, 385 (1814).

2 Ann. de chim. et de phys. and Journ. de phys., 79, 113 (1814). The paper was read before the Academy in March, 1814.

${ }^{3}$ Schweigger's Journal, 12, 349 (1813).

4 Assisted by Dr. R. D. MacLaurin, Prof. S. F. Howard, C. D. Kennedy and J. C. Reed. 
partment would require many analyses, it was desirable that the methods adopted should be reasonably short and simple, though accuracy would be the controlling factor. The literature on the determination of arsenic was reviewed at some length. The results, while somewhat overwhelming, can be roughly summarized under gravimetric methods, volumetric methods and processes for the elimination of substances liable to effect the determination. A classification of this character is open to criticism but will serve the purpose intended.

The gravimetric methods include the hydrogen sulfide precipitation of arsenous acid ${ }^{x}$ weighable as arsenous sulfide after removal of the excess sulfur; the Neher modification ${ }^{2}$ of the Bunsen method, ${ }^{3}$ precipitating arsenic acid with hydrogen sulfide, weighable as arsenic sulfide; the modified Levol method, precipitating arsenic acid with "magnesia mixture" weighable as magnesium pyro-arsenate; and the Werther method, ${ }^{4}$ precipitating arsenic acid with uranyl acetate weighable as uranyl pyro-arsenate. The inherent faults of the sulfide methods render them impractical. The modified Levol method, the most prominent of the gravimetric, is complicated, tedious and tends towards low results. All of these methods are time-consumers and none of them appear to have met with favor, having of late been almost entirely superseded by volumetric.

The volumetric methods include that of Kessler, ${ }^{5}$ oxidizing arsenous acid with potassium bichromate and titrating the excess chromic acid with standard ferrous sulfate, using potassium ferricyanide to determine the end-point; the permanganate method, titrating arsenous acid with standard potassium permanganate to a rose color; the Mohr method, titrating arsenous acid with standard iodine in the presence of sodium bicarbonate, using starch paste as indicator; the Bunsen method, 6 based on the difference in amount of chlorine evolved from hydrochloric acid by a given weight of potassium bichromate in the presence of arsenous acid, the gas being conducted into potassium iodide and the free iodine titrated with standard sodium thiosulfate, using starch paste as indicator; the Krickhaus method,? reducing arsenic acid to arsenous with hydrochloric acid and potassium iodide and titrating the free iodine with standard thiosulfate; the Bennett modifications of the Pierce method, ${ }^{9}$ precipitating arsenic acid with silver nitrate and titrating the silver in the precipitate with potassium sulphocyanate according to Volhard; ${ }^{\text {ro }}$ and the Bödeker method, ${ }^{11}$ titrating arsenic acid with standard uranyl nitrate using potassium ferrocyanide to determine the end-point. The Kessler and Bödeker methods are objectionable in their re-

\footnotetext{
1 Fresenius, "Quan. Chem. Anal."

2 Zischr. anal. Chem., 32, 45 (1893).

3 Ann. Chem. Pharm., 192, 305.

4J. prakt. Chem., 43, 346 (1848).

5 Pogo. Ann., 118, [4] 17 (1863)

6 Ann. Chem. Pharm., 86, 290

${ }^{7}$ Eng. Min. Jour., 90, 357. See Sutton for earlier references.

s. Am. Chem. Soc., 21, 431 (1899),

Proc. Coll. Sci. Soc., Vol. I.

10 Liebig's Ann., 190, 1 (1878).

"1 Ann. Chem. Pharm., 117, 195,
}

quirement of an "outside" indicator. The Bunsen and Bennett methods are lengthy and demand very careful manipulation. The permanganate titration is not as sensitive as the iodine and the Krickhaus method offers no advantages in its application to arsenic acid over a similar reduction and titration with iodine. In other words, the iodine titration method (Mohr) seemed to us rather superior to any other in point of accuracy, manipulation and time, and was adopted for the work in view.

There are a number of processes that are noted more particularly as a means of eliminating impurities likely to effect the arsenic determination, among which may be mentioned the distillation processes of Fischer, ${ }^{2}$ Piloty and Stock, ${ }^{2}$ Stead ${ }^{3}$ and Jannasch and Seide1, 4 using hydrochloric acid in connection with reducing substances such as ferrous salts, hydrogen sulfide, and potassium bromide and hydrazine hydrochloride. The above list of methods is far from complete but attention has been called to practically every type applicable to commercial products.

\section{IODINE METHOD (MOHR).}

As previously stated, the iodine method appeared to offer the greatest advantages and was selected. A clear understanding of the character and limitations of the reaction underlying the method is necessary at the outset. Iodine is an indirect oxidizer, acting on the elements of water with the formation of hydriodic acid and the liberation of oxygen.

$$
\mathrm{As}_{2} \mathrm{O}_{3}+{ }_{4} \mathrm{I}+{ }_{2} \mathrm{H}_{2} \mathrm{O}=\mathrm{As}_{2} \mathrm{O}_{5}+{ }_{4} \mathrm{HI} \text {. }
$$

The oxidation cannot be conducted in an acid or neutral solution because of the reversible action of the hydriodic acid. If the latter is neutralized with sodium bicarbonate as rapidly as produced, the reaction will proceed to completion. Caustic alkali or carbonate cannot be employed as they absorb iodine, the former being especially active. The reaction between starch and iodine in the presence of hydriodic acid or soluble iodide is one of the most sensitive in analytical chemistry, forming the characteristic blue iodide starch. A more delicate indicator could not be desired. Since the method. was first applied to the analysis of arsenicals numerous modifications have been devised to insure complete solution of the arsenic, to prevent oxidation, to eliminate or render inocuous substances that might effect the titration, and to enlarge its field of application so as to readily include the arsenates. The Association of Official Agricultural Chemists began work on insecticides in 1899 and has rendered valuable service.

\section{NEW PROCESSES.}

The introduction of the Thorn Smith process ${ }^{5}$ marked a turning point in the analysis of arsenicals. It was intended particularly for Paris green and is the official method for that substance. Solution of the arsenic is effected by boiling the sample with a slight excess of sodium hydroxid which readily unites with

\footnotetext{
1 Ztschr. anal. Chem., 21, 266 (1882).

2 Ber. deut. chem. Gesell., 30, 1649 (1897).

3 Sutton, "Vol. Anal.," Ed. 9, 159 (1904),

4 Ber. deut. chem. Gesell., 43, 1218 (1910).

${ }^{5}$ J. Am. Chem. Soc., 21, 769 (1899).
} 
the free arsenous acid and also with the combined, after displacing the copper. In presence of a reducing substance like sodium arsenite, the copper is precipitated as cuprous oxide and a portion of the arsenous acid oxidized to arsenic. This oxidation necessitates a subsequent reduction of the filtrate with hydrochloric acid and potassium iodide (hydriodic acid) and the removal of the excess iodine with thiosulfate. The solution is neutralized with dry sodium carbonate, an excess of sodium bicarbonate added, and titrated with iodine. The process is accurate, though the double titration is objectionable.

Avery and Beans devised a very ingenious process ${ }^{5}$ noted for its simplicity. The Paris green is pulverized, solution effected with concentrated hydrochloric acid in the cold, neutralized with sodium carbonate, the precipitated copper redissolved with sodium potassium tartrate and titrated as usual. The copper held by the alkaline tartrate colors the solution but does not effect the titration. Hydrochloric acid, however, is a poor solvent for free arsenic and unreliable, which constitutes a very serious objection to the process. Avery noted this error and advised $^{2}$ that samples showing a tendency to separate white arsenic should be treated with $\mathrm{N} / 2$ hydrochloric acid, 5-10 cc. for each 0.1 gram, and boiled gently. In case arsenic remains undissolved, a cold saturated solution of sodium acetate, 3 grams salt for each 0.1 gram of substance, is added and boiling continued until solution is effected. By another modification ${ }^{3}$ suggested by Avery and reported by Thatcher, 4 I gram sample is boiled 5 minutes with $25 \mathrm{cc}$. of sodium acetate solution $(\mathrm{I}-2)$, dissolving the free arsenic which is removed by filtration. The residue is dissolved in dilute hydrochloric acid and both solutions titrated.

Haywood attempted, in several ways, ${ }^{5}$ to modify the original Avery-Beans process so as to insure solution of the free arsenic. After treating the sample with a slight excess of hydrochloric acid at laboratory temperature, sodium carbonate was added and the solution boiled. In another case sodium bicarbonate was employed but the results were unsatisfactory in both substances, due to more or less reduction of copper and accompanying oxidation of arsenous acid. Accurate results were secured, however, by filtering off the hydrochloric acid solution and boiling the residue with 5 grams of sodium bicarbonate, titrating both solutions.

Haywood proposed still another modification ${ }^{8}$ which might be considered a simplified Avery-Thatcher process, ${ }^{7}$ 0.4 gram sample is boiled 10 minutes with $25 \mathrm{cc}$. sodium acetate solution $(\mathrm{I}-2)$ to dissolve free arsenic and concentrated hydrochloric acid carefully added until solution is effected. After neutralizing with a solution of sodium carbonate, avoiding an

1 J. Am. Chem. Soc., 23, 485 (1901).

2 Ibid., 25, 1096 (1903).

3 Optional official method, Assoc. Off. Agr. Chem.

4Proc. Assoc. Off. Agr. Chem., 20, 196,(1903).

of. Am. Chem. Soc., 25, 963 (1903).

- Proc. Assoe. Off. Aor. Chem., 20, 197 (1903). Optional official method of the Association.

7 Loc. cit. excess, alkaline tartrate and sodium bicarbonate are added and titrated as usual.

The Avery, Avery-Thatcher and Avery-Haywood processes employ the same reagents, differing only in their application. The coöperative investigation ${ }^{x}$ of the association in 1904 showed that the three above modifications, together with the Haywood, gave closely agreeing results with little if any advantage in the two-solution processes over the one. In I905 the results ${ }^{2}$ with the Avery-Thatcher and Avery-Haywood modifications were not as satisfactory though the average difference was not excessive.

On comparing the merits of the Thorn-Smith process and various modifications of the Avery-Beans with apparently little choice as to accuracy, the Avery or Avery-Haywood process, with one titration of a single solution, certainly appeals to chemists in "control" work from the standpoint of manipulation, possible mechanical losses and time. This does not warrant any less care in conducting the analysis but if anything demands greater attention. The essential features of the Avery-Haywood process have been employed at the Massachusetts station for the work on arsenites, though considerably modified as to detail.

\section{PRACTICE AT MASSACHUSETTS STATION.}

Having adopted. Thatcher's suggestions ${ }^{3}$ as to ratio of sample to acetate solution, $I-25$, and finding $25 \mathrm{cc}$. rather inadequate for proper boiling and agitation, double quantity of each is taken. To prevent slight loss of sample in transferring to flask, due to both adhesion and dusting, boats of folded filter paper are employed and found very serviceable, particularly for Paris green and arsenic for standard solution. After boiling the solution 5 minutes with acetate, the directions call for the careful addition of concentrated hydrochloric acid until solution is effected. Such a procedure in our hands gave extremely variable results and generally a low test for arsenic. This error necessitated several weeks of experimenting and was found to be due to the addition of concentrated acid, dilute acid ( $1-3)$ giving uniform results in practically every instance and a higher test. Probably this has been one of the sources of trouble with the chemists reporting on association samples by the above process in past years. Neutralizing with sodium carbonate, in dry form or concentrated solution, will introduce an error if added in excess. The use of sodium bicarbonate is preferable for the purpose as the latter salt does not absorb iodine and eliminates an unnecessary reagent. As concentration has a certain influence on titration, it is advisable to maintain approximately the same volume in every case. The tendency of some solutions to become muddy on titration can often be relieved by additional bicarbonate, though the conditions involved seem to have no appreciable influence on the results. The quality of all reagents employed in the determination should be proved by blank tests which

\footnotetext{
1 Proc. Assoc. Off. Agr. Chem., 21, 98 (1904)

2 Ibid., 22, 27 (1905).

Ibid., 21, 99 (1904).
} 
should not exceed o.Io cc. iodine solution for the amounts employed. Some lots of bicarbonate have been found unfit for such work. Due recognition should be given the blank in calculating results.

Considerable trouble is often experienced in determining insoluble matter with hydrochloric acid due to the splitting off of white arsenic, especially with Paris green. To offset the difficulty it was found advisable to combine the determination with that of preparing the arsenic solution by simply filtering off the residue. The points noted above may be briefly summarized:

Transfer 2 grams of finely pulverized sample together with $50 \mathrm{cc}$. of sodium acetate (I-2) to a $500 \mathrm{cc}$. graduated flask and boil 5 minutes. Cool under tap, add about $60 \mathrm{cc}$. of hydrochloric acid $(\mathrm{I}-3)$ and shake until solution is effected. Make to volume and filter. Pipette 25 or $50 \mathrm{cc}$. into an Erlenmeyer flask, neutralize with dry sodium bicarbonate, add $25 \mathrm{cc}$. of sodium potassium tartrate ${ }^{\mathrm{I}}$ (I-IO) to redissolve precipitated copper, approximately 3 grams of sodium bicarbonate, water sufficient to make a volume of Ioo cc., 2 cc. starch paste $(I-200)$ and titrate with $N / 20$ iodine to a permanent blue color. Toward the end of the reaction cork the flask and shake vigorously to insure proper end-point. Calculate results as arsenous oxide. The residue in the graduated flask is brought onto the filter, well washed, calcined in a porcelain crucible and weighed as insoluble matter.

The above process has given excellent results with copper aceto-arsenite, copper arsenite and calcium arsenite. Sodium acetate does not prevent hydrolysis of copper and calcium arsenites as in the case of Paris green, but serves to take up free arsenic. The presence of such impurities as cuprous and ferrous compounds, sulfurous and nitrous acids or other oxidizable substances is a source of error by the iodine titration method.

\section{IODINE METHOD FOR ARSENATES.}

The increasing use of lead arsenate as an insecticide resulted in a demand for a rapid volumetric method for the determination of the arsenic acid. The Gooch and Browning process, ${ }^{2}$ as modified by Haywood, ${ }^{3}$ serves to readily reduce arsenic acid to arsenous in which form the iodine titration method is applicable. The process, in our hands, did not at first prove satisfactory but eventually yielded concordant results after minor changes. As the differences are largely a matter of detail not involving principle, only the modified process will be given.

Transfer 2 grams of finely ground sample together with $60 \mathrm{cc}$. of nitric acid $(\mathrm{I}-3)$ to a $500 \mathrm{cc}$. graduated flask, bring to boil, cool, make to volume and filter. Pipette 50 or $100 \mathrm{cc}$. into a $150 \mathrm{cc}$. Jena Griffin beaker, add to cc. of sulfuric acid (2-I), evaporate, heat in an air bath at $150-200^{\circ} \mathrm{C}$. to expel last traces of moisture, and then on asibestos board to the appearance of dense white fumes to insure complete removal of nitric acid. Add a small quantity of

1 Used only with the copper arsenites.

2 Am. J. Sci., 40,66 (1890).

3 Proc. Assoc. Off. Agr. Chem., 23, 165 (1906). Provisional method of the Association. water and when cold, filter through a sugar tube under suction into a $300 \mathrm{cc}$. Erlenmeyer flask and wash to about roo cc. Add ro cc. of potassium iodide $(165-1000)$ and boil until free iodine is expelled-solution practically colorless-with the reduction of arsenic to arsenous acid.

$$
\mathrm{As}_{2} \mathrm{O}_{3}+{ }_{4} \mathrm{HI}=\mathrm{As}_{2} \mathrm{O}_{3}+{ }_{4} \mathrm{I}+{ }_{2} \mathrm{H}_{2} \mathrm{O} \text {. }
$$

Dilute, cool immediately, neutralize with sodium hydroxid and render slightly acid with sulfuric acid. Add starch paste and if any free iodine remains, add dilute $(N / 50)$ thiosulfate carefully with vigorous shaking to the absence of blue color.

$$
2 \mathrm{I}+2 \mathrm{Na}_{2} \mathrm{~S}_{2} \mathrm{O}_{3}=\mathrm{Na}_{2} \mathrm{~S}_{4} \mathrm{O}_{8}+2 \mathrm{NaI} \text {. }
$$

Add excess of sodium bicarbonate and titrate as usual with $N / 20$ iodine, reporting as arsenic oxide. The residue in the graduated flask is brought onto the filter, washed, calcined and weighed as insoluble matter.

Care should be taken to add sufficient sulfuric acid to cover the bottom of the beaker when heated on asbestos. A decided excess of acid is also necessary when boiling with potassium iodide to insure vigorous action and rapid volatilization of iodine. Neutralization with caustic soda is permissible under the conditions described. The hydroxid is a much more convenient and rapid agent than the carbonate. Practically no difference was noted in the titration when the lead sulfate was allowed to remain, but the data at hand does not cover a sufficient number of samples to warrant a statement that this will always hold true.

The iodine method, as modified for arsenites and arsenates, has been given a careful study and proved repeatedly in the work at the Massachusetts station to yield excellent results in the analysis of the insecticides mentioned, if reasonable attention is paid in following the details. While no radical changes in the method have been recommended, this article is offered in hopes that some of the points noted may prove of assistance to other analysts working along similar lines.

Department of Plant and Animal Chemistry,

Massachusetts Agricultural EXperiment Station.

\section{PURIFICATION OF INSOLUBLE FATTY ACIDS.}

By E. B. Holland.

Workers in oils and fats experience the same diffculty in obtaining chemically pure products as investigators in other lines of organic chemistry. The best insoluble fatty acids on the market-judging from our experience-are unsatisfactory in both physical characteristics and neutralization number. In general appearance the acids that are offered resemble granulated curd, though varying in color from white to yellow, and contain considerable dust and dirt. The molecular weight, as measured by titration, in an alcoholic solution, may deviate from the theoretical by ro-r 5 points. These statements apply to chemicals marked "C. P." and bearing the name of a reputable manufacturer or dealer.

The writer required stearic, palmitic, myristic, 